Article

\title{
Potential of Combining Optical and Dual Polarimetric SAR Data for Improving Mangrove Species Discrimination Using Rotation Forest
}

\author{
Hongsheng Zhang ${ }^{1,2}$, Ting Wang ${ }^{1}$, Mingfeng Liu ${ }^{1}$, Mingming Jia ${ }^{3}{ }^{(1)}$, Hui Lin ${ }^{1,2,4, *}$, \\ LM Chu ${ }^{5}$ and Adam Thomas Devlin ${ }^{1}$ \\ 1 Institute of Space and Earth Information Science, The Chinese University of Hong Kong, \\ Shatin, New Territories, Hong Kong; zhangstream@gmail.com (H.Z.); wangtingwhu@126.com (T.W.); \\ mingfengliu@link.cuhk.edu.hk (M.L.); adam_devlin@cuhk.edu.hk (A.T.D.) \\ 2 Shenzhen Research Institute, The Chinese University of Hong Kong, Shenzhen 518057, China \\ 3 Key Laboratory of Wetland Ecology and Environment, Northeast Institute of Geography and Agroecology, \\ Chinese Academy of Sciences, No. 4888, Shengbei Street, Changchun 130102, China; jiamingming@iga.ac.cn \\ 4 Key Laboratory of Poyang Lake Wetland and Watershed Research, Ministry of Education, \\ Jiangxi Normal University, Nanchang 330022, China \\ 5 School of Life Sciences, The Chinese University of Hong Kong, Shatin, New Territories, Hong Kong, China; \\ leemanchu@cuhk.edu.hk \\ * Correspondence: huilin@cuhk.edu.hk; Tel.: +852-39436010
}

Received: 18 November 2017; Accepted: 13 March 2018; Published: 16 March 2018

\begin{abstract}
Classification of mangrove species using satellite images is important for investigating the spatial distribution of mangroves at community and species levels on local, regional and global scales. Hence, studies of mangrove deforestation and reforestation are imperative to support the conservation of mangrove forests. However, accurate discrimination of mangrove species remains challenging due to many factors such as data resolution, species number and spectral confusion between species. In this study, three different combinations of datasets were designed from Worldview-3 and Radarsat-2 data to classify four mangrove species, Kandelia obovate (KO), Avicennia marina (AM), Acanthus ilicifolius (AI) and Aegiceras corniculatum (AC). Then, the Rotation Forest (RoF) method was employed to classify the four mangrove species. Results indicated the benefits of dual polarimetric SAR data with an improvement of accuracy by 2-3\%, which can be useful for more accurate large-scale mapping of mangrove species. Moreover, the difficulty of classifying different mangrove species, in order of increasing difficulty, was identified as $\mathrm{KO}<\mathrm{AM}<\mathrm{AI}<\mathrm{AC}$. Dual polarimetric SAR data are recognized to improve the classification of AI and AC species. Although this improvement is not remarkable, it is consistent for all three methods. The improvement can be particularly important for large-scale mapping of mangrove forest at the species level. These findings also provide useful guidance for future studies using multi-source satellite data for mangrove monitoring and conservation.
\end{abstract}

Keywords: mangrove species; rotation forest; Worldview-3; Radarsat-2; Hong Kong wetlands

\section{Introduction}

Mangrove forests comprise one of the most productive and important planetary ecosystems because of their ecological, biological and socioeconomic significance [1-3]. They provide important ecological services including: (1) shoreline stabilization to reduce the impacts of natural disasters; (2) habitat provision for invertebrates, fish and other coastal wildlife; and (3) carbon sequestration for the ocean [1]. However, mangrove forest cover has decreased dramatically during the past century due to various human activities such as urbanization, agriculture conversion and tourism [1,2]. Monitoring the spatial distribution of mangrove forests is imperative to understand their vegetation dynamics better, such as 
succession, deforestation, stand density and health conditions, as well as further understanding the ecological services they provide $[1,2,4,5]$. Conventionally, a number of approaches has been proposed to monitor and analyze mangrove forests using remote sensing data from various data sources at different spatial, spectral and temporal resolutions. Regarding the remote sensing data sources, most previous studies can be grouped into two main categories, those employing optical data (e.g., multispectral and hyperspectral data) and those using Synthetic Aperture Radar (SAR) data (single- and multi-polarimetric data). High resolution satellite data have been used for discrimination of mangrove species [6-11], since they contained rich textural information allowing identification of various species. Hyperspectral satellite data were also intensively employed for mangrove species discrimination [12-14]. Additionally, coarser resolution satellite data were applied to map the spatial dynamics of mangrove forests using mixed analysis and object-oriented approaches [1,4,5,15-17]. Additionally, SAR satellite data have been increasingly used to study mangroves since longer wavelength (e.g., $\mathrm{C}$ and L bands) active microwave signals are sensitive to the surface and vertical structures and, hence, biomass of mangrove forests. Different frequencies (C-/L-/P-band) of microwave radar have also been used to examine different mangrove species (Laguncularia, Avicennia and Rhizophora) using airborne multi-polarimetric SAR data [18-22]. The tree density, basal area, tree height, tree DBH and biomass were used to test the responses from different frequencies of SAR data. With a shorter wavelength and less penetration, the C-band was found to be more sensitive to crown characteristics, canopy structure and canopy heterogeneity [18-20]. The radiative nature of C-band backscatters was investigated in different vegetation, such as wheat and burned forests regarding their canopy $[23,24]$. This radiative nature was also modelled based on the C-band backscattering with different vegetation, such as the Michigan Microwave Canopy Scattering (MIMICS) model towards the soybean canopy using Spaceborne Imaging Radar-C (SIR-C) data [25] and the Water Cloud Model (WCM) based on the boreal forests using ERS-1 data [26]. Polarimetric data were applied to study mangrove species by analyzing different polarizations in the coast of French Guiana [19]. Biophysical parameters such as Leaf Area Index (LAI) and biomass were also calculated from multi-polarimetric ENVISAT and ALOS data to study the health of mangroves [27,28]. In particular, optical and SAR remote sensing data provide complementary information to each other [29-31], and thus, their combined use can enhance better accuracy for mangrove monitoring. Both Landsat and Radarsat-1 data were applied to conduct a comprehensive classification over coastal forests in the Brazilian Amazon Region [32]. Landsat and ENVISAT were also combined together to analyze mangrove conditions [33]. More recently, hyperspectral data were combined with ENVISAT data to map mangrove species in Hong Kong [34,35]. However, the dual polarimetric SAR data are yet to be investigated to explore their potentials for mangrove species classification. This study aims to evaluate this potential regarding different mangrove species (Kandelia obovate, Avicennia marina, Acanthus ilicifolius and Aegiceras corniculatum) using the rotation forest method, and thus provide a technical reference for studies employing the C-band dual polarimetric Radarsat-2 data for mangrove monitoring.

\section{Study Area, Data and Preprocessing}

\subsection{Study Site}

The Mai Po Marshes Nature Reserve (MPMNR), $22^{\circ} 29^{\prime} 23.75^{\prime \prime} \mathrm{N}, 114^{\circ} 1^{\prime} 42.71^{\prime \prime} \mathrm{E}$, was selected as the study site for mangrove species discrimination in this study. It is located in the northwestern part in the New Territories, Hong Kong, bordering on the inner Deep Bay between Shenzhen and Hong Kong (Figure 1). The Mai Po and inner Deep Bay are listed as a Wetland of International Importance under the Ramsar Convention, which was the first Ramsar Site Strategy and Management Plan (RSMP) in Hong Kong $[16,35,36]$. There are around 350 ha of mangrove forests in the Core Zone of the MPMNR. The whole wetland is under the influence of a humid subtropical climate with rainy and cloudy weather throughout the year, which has hindered the applications of any form of optical satellite remote sensing [16,37]. Additionally, the area is located on the Pearl River Estuary (PRE), which has been affected by the dramatic urbanization of the Pearl River Delta (PRD) region, which is 
affected by serious water and air pollution. Moreover, sea level change and temperature increase as a result of climate change threaten wetlands through sedimentation and erosion in the intertidal area [36]. To improve the management of the region and enhance the ecological values of the wetland, the MPMNR is structured into five different zones by the Agriculture, Fisheries and Conservation Department (AFCD), including the Core Zone, Biodiversity Management Zone, Wise Use Zone, Public Access Zone and Private Land Zone.

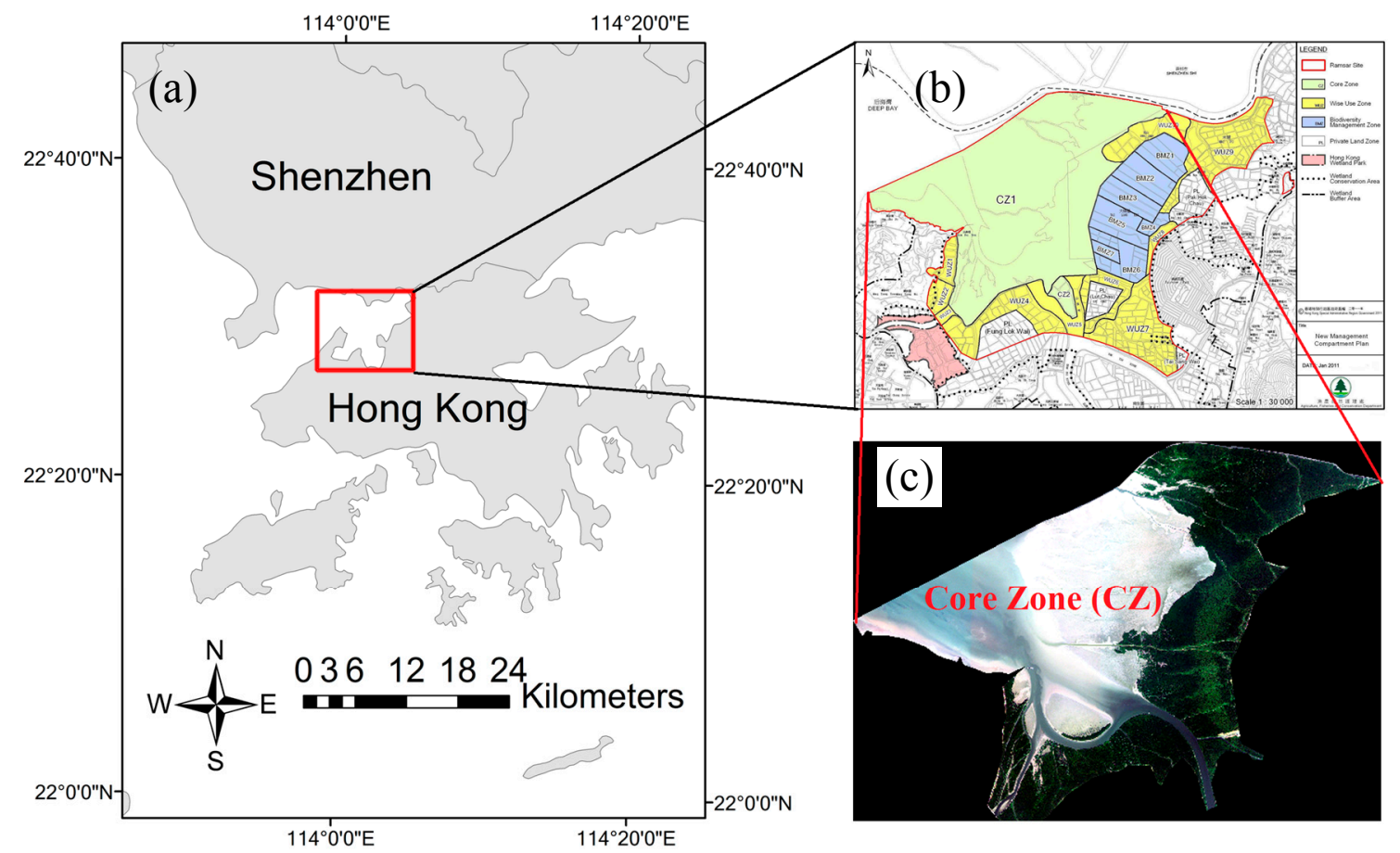

Figure 1. Location of the study site in Hong Kong: (a) map showing its geographical setting in the Pearl River Estuary (PRE), (b) a fine-scale map of the Mai Po Marshes Nature Reserve (MPMNR), modified from the government report published by the Agriculture, Fisheries and Conservation Department (AFCD, 2011), and (c) a true color image from Worldview-3 data.

\subsection{Field Data}

The MPMNR is the biggest mangrove forest in Hong Kong and one of the few extensive mangroves in southern China [16,38,39]. Among these management zones, the Core Zone was selected as the major study site where a total of seven mangrove species were reported by the local government $[35,36]$. However, only four species distributed over a wide area can be identified from satellite images (Figure 2), including Kandelia obovate (KO), Avicennia marina (AM), Acanthus ilicifolius (AI) and Aegiceras corniculatum (AC). A set of data was collected by two rounds of field surveys over the MPMNR on 11 July 2013 and 10 November 2015. Since the Core Zone area is strictly protected by the Hong Kong government, a quadrat survey was not allowed to be used to investigate the biomass of mangroves. Only GPS receivers and cameras were used to record the field data by marking the species of mangroves during our two survey rounds. A total of 718 samples were collected for six classes, including Mudflat (MUD), Water body (WAT) and four mangrove species, namely KO, AM, AI and AC. In particular, the collection time of field data and satellite data, to be discussed in the next section, had a time difference of about two years. However, the Core Zone has been highly protected since 1995 [36,40], indicating minimal impacts from local human activities. Based on previous investigations of the mangrove biomass that demonstrated that the biomass of local mangrove forests did not change significantly [41,42], we assume that the two-year difference between the field data and satellite data does not have a significant impact on our study. 


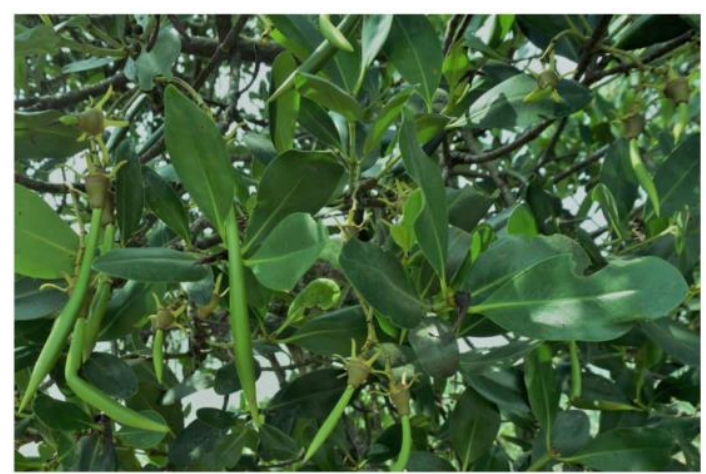

(a) Kandelia obovate (KO)

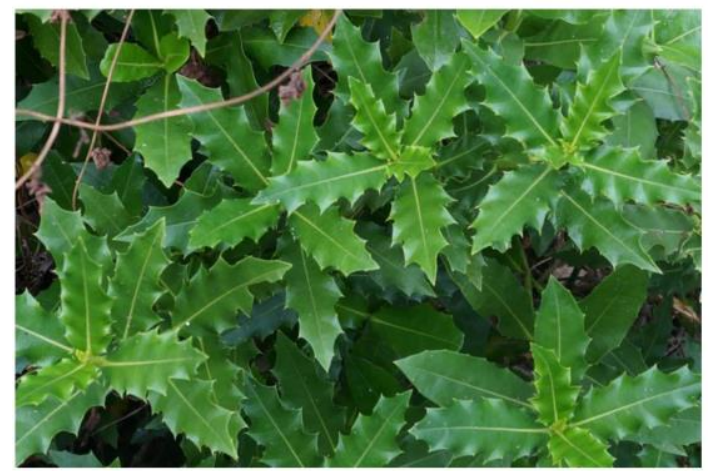

(c) Acanthus ilicifolius (AI)

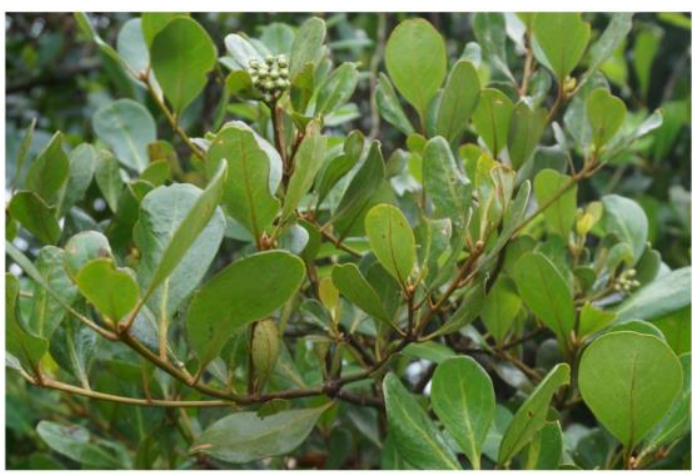

(b) Avicennia marina(AM)

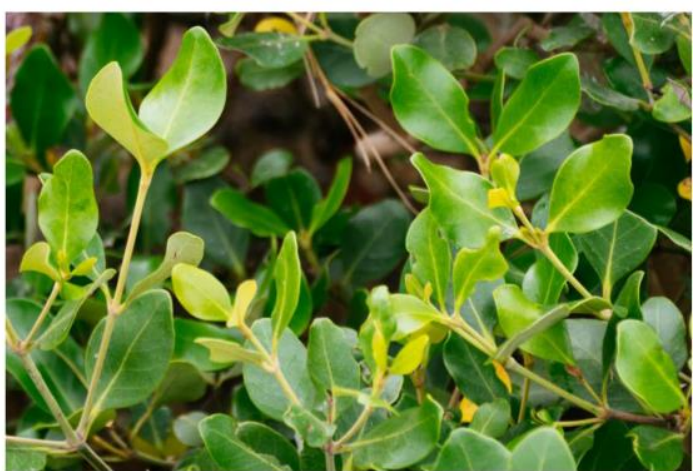

(d) Aegiceras corniculatum (AC)

Figure 2. Photos of the four mangrove species given close consideration in the field survey, (a) is Kandelia obovate (KO), (b) is Avicennia marina (AM), (c) is Acanthus ilicifolius (AI) and (d) is Aegiceras corniculatum (AC).

\subsection{Dataset and Preprocessing}

Worldview-3 data were employed as the optical data, while the dual polarimetric SAR data from Radarsat-2 were used as the SAR data to classify the four mangrove species. The Worldview-3 data, collected on 1 January 2015, have eight multispectral bands at 1.6-m resolution and one panchromatic band at $0.4-\mathrm{m}$ resolution. To pre-process the eight-band product, a radiometric correction has been conducted by the data provider DigitalGlobe Corporate (U.S.). Additionally, a calibration was applied to convert the data into absolute radiance in the units of $(\mathrm{uW}) /\left(\mathrm{cm}^{2} \times \mathrm{nm} \times \mathrm{sr}\right)$, using the metadata file provided by the data provider. The calibration was conducted by the software ENVI 5.0 with the metadata file. The Radarsat-2 data used in this study are dual-polarimetric products with $\mathrm{HH}$ and $\mathrm{HV}$ polarizations, collected on 8 November 2014. The resolution of geo-referenced Radarsat-2 data is about $8 \mathrm{~m}$. To preprocess the SAR images, basic radiometric correction and calibration processes were conducted, and thus, the data were transformed to units of $\mathrm{dB}$. Considering the uncertainty of the speckle noises in SAR images, speckle noises were filtered by the enhanced Lee filter, with a window size of $3 \times 3$ pixels. Multi-look techniques were also applied with two looks in the azimuthal direction and one look in the range direction. There was approximately a two-month difference of the imaging dates between the Worldview-3 and Radarsat-2 data; however, as they occurred in the same season, we assumed that there was no significant change of the mangrove forests within this period. Finally, both the optical and SAR data were geocoded and co-registered using the Universal Transverse Mercator (UTM) projection (Zone 49N) and Datum World Geodetic System 1984 (WGS84). The detailed parameters of the data are provided in Table 1. Since the two datasets were of different spatial resolutions, according to our previous experiences in integrating optical and SAR data [29], the Worldview-3 data were resampled to $8 \mathrm{~m}$ as the Radarsat-2 data. 
Table 1. Details of the remote sensing data.

\begin{tabular}{cclc}
\hline Satellite & \multicolumn{1}{c}{ Date } & \multicolumn{1}{c}{ Spectral/Polarizations } & Resolution \\
\hline & & Coastal: $400-450 \mathrm{~nm}$ & \\
& & Blue: $450-510 \mathrm{~nm}$ \\
& Green: $510-580 \mathrm{~nm}$ & \\
\multirow{2}{*}{ Worldview-3 } & \multirow{2}{*}{ 1 January 2015 } & Yellow: $585-625 \mathrm{~nm}$ & $1.6 \mathrm{~m}$ \\
& & Red: $630-690 \mathrm{~nm}$ \\
& & Red Edge: 705-745 nm & \\
\cline { 3 - 4 } & & Near Infrared 1: 770-895 nm & \\
& & Near Infrared 2: $860-1040 \mathrm{~nm}$ & \\
\hline Radarsat-2 & 8 November 2014 & HH, HV & $8 \mathrm{~m}$ \\
\hline & & & \\
& & & \\
\end{tabular}

\section{Methods}

The methodological framework used in this study is illustrated in Figure 3. There are four main parts: the preprocessing of satellite data, the feature extraction for optical and SAR data, the mangrove species classification and the accuracy assessment using the field data. The preprocessing of both optical and SAR data was detailed in Section 2.3, and this section will describe the other three parts of the methods.

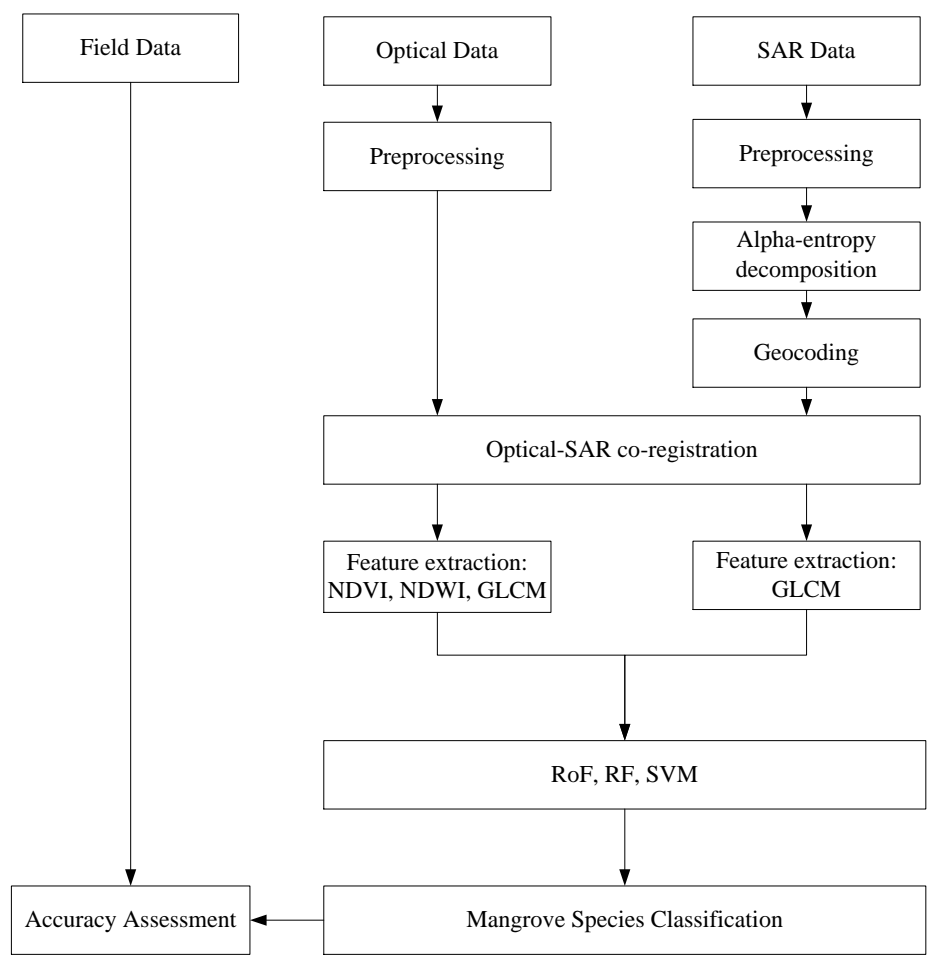

Figure 3. Methodological framework of mangrove species discrimination. RoF, Rotation Forest.

\subsection{Feature Extraction from Optical and Polarimetric SAR Data}

Spectral features were extracted from optical data by analyzing the spectral reflectance or digital numbers for each band based on a single pixel. Spectral features are often based on some of the important bands that characterize the features of one land cover type, such as vegetation, water or soil. In this study, the Normalized Difference Vegetation Index (NDVI) and Normalized Difference Water Index (NDWI) were employed as the spectral features for optical data $[43,44]$. There are two different ways of calculating NDVI and NDWI, corresponding to the standard band NIR1 (772-890 nm) and the additional band NIR2 (866-954 nm) in Worldview-3 data. 
Textural features are often beneficial as land targets in high spatial resolution images, as they provide rich spatial details. In this study, as shown in Figure 3, texture features were extracted from both optical and SAR data. Generally, there are numerous textural measurement approaches performed in other studies, while the Grey Level Co-occurrence Matrix (GLCM) approach [45] has been widely employed and proven to be helpful in many study cases. One typical issue when applying GLCM analysis is the determination of the window size to calculate the co-occurrence matrix and the texture-related parameters of the intended target. Since the aim of this study is to evaluate the potential of polarimetric features from SAR data and the complementation between optical and SAR data for mangrove species mapping, we did not apply a comprehensive analysis of the optimization of these GLCM parameters. Empirically, we applied a 3-by-3 window to calculate the GLCM, and eight texture measures based on GLCM were employed, including mean value, variance, homogeneity, contrast, dissimilarity, entropy, angular second moment and correlation.

In polarimetric SAR data, the size and shape of mangrove leaves differ from one species to another, while the height and density of mangrove stands also differ among species. These mangrove tree features may lead to different scattering mechanisms, which are reflected in the polarimetric features. Various scattering types can be characterized from different decomposition components, including the surface scattering, volume scattering and double bounce scattering. In general, dual polarimetric SAR data can be represented in the form of a scattering matrix (S), which can be further transformed into a coherency matrix $(T)$. Polarimetric features can be extracted from the polarimetric SAR data based on the decomposition of the covariance matrix or coherency matrix by applying various decomposition methods. It should be noted that the polarimetric decomposition was applied before the SAR data were geocoded, while the texture features were extracted after the geocoding and the co-registration, as shown in Figure 3.

$$
T=\left[\begin{array}{cc}
\left\langle S_{H H} S_{H H}^{*}\right\rangle & \left\langle S_{H H} S_{H V}^{*}\right\rangle \\
\left\langle S_{H V} S_{H H}^{*}\right\rangle & \left\langle S_{H V} S_{H V}^{*}\right\rangle
\end{array}\right]
$$

In this study, the alpha-entropy decomposition based on the Cloude-Pottier decomposition approach has been widely applied to classify polarimetric SAR data [46,47]. The alpha, entropy $(H)$ and anisotropy $(A)$ are calculated based on the eigenvalues $\left(\lambda_{1}\right.$ and $\left.\lambda_{2}\right)$ and eigenvectors of coherency matrix $T$ (Equations (2) and (3)) and are able to reflect the scattering information and the complexity of land surfaces.

$$
\begin{gathered}
\text { Alpha }=\alpha\left(P_{1}-P_{2}\right)+P_{2} \frac{\pi}{2} \\
H=P_{1} \log _{2} P_{1}+P_{2} \log _{2} P_{2} \\
A=\frac{\lambda_{1}-\lambda_{2}}{\lambda_{1}+\lambda_{2}}
\end{gathered}
$$

\subsection{Mangrove Species Classification Using Rotation Forest}

Rotation Forest (RoF) is an ensemble machine learning method based on a base decision tree classifier by randomly splitting the samples into K subsets, and Principal Component Analysis (PCA) is applied to each of the subsets for feature extraction [48]. RoF has been applied to the classification of remote sensing images [49]. The detailed technical steps to build up an RoF can be found in $[48,49]$. In this study, the Classification And Regression Tree (CART) method was selected as the base classifier. Typically, two key parameters need to be set to achieve good performance of RoF, the number of subsets, $\mathrm{K}$, and the percentage of information used for building up the classifier after the transformation of PCA. In this study, $\mathrm{K}$ was set to be 30 by empirically testing a series of different values from $10-50$. The percentage of preserved information after PCA was set to 75\% according to the recommendation in [49], where it was reported that too small of a percentage value cannot maintain the useful information while too large of a percentage value cannot yield an obvious improvement of RoF.

In order to evaluate the impacts of these new methods on the mangrove species classification, another two advanced machine learning methodologies, Support Vector Machine (SVM) [50] and Random Forest 
(RF) [51] were comparatively employed to carry out the classification. Both SVM and RF were set with optimized parameters based on previous studies. For instance, for the SVM method, the Radial Basis Function (RBF) was used as the kernel function. Additionally, there are two key parameters that can influence the performance of SVM, the gamma $(G)$ in RBF and the penalty $(C)$ during the identification of support vectors. In this study, the optimal $G$ and $C$ were chosen using an empirical grid-search method that was previously used in our research [52]. Moreover, a one-against-rest strategy was employed to implement the multi-class SVM [53]. For the RF method, the performance depends on two key parameters, the number of decision trees $(T)$ and the number of variables/features $(m)$, to determine the decision rules at each node. In our previous study, we analyzed the optimal setting of $T$ and $m$ by combining optical and SAR data. This study followed the recommendation that $T$ should be bigger than 20 and $\mathrm{m}$ should be determined by Equation (5), where $M$ is the total number of features for each sample [37]. In particular, RoF is different from RF in its technical details, although both of them construct a set of decision trees to form a forest with a certain process of randomness. First, RoF applies PCA on each subset of samples for feature extraction, while RF applies random selection of features instead of feature extraction. Second, RoF adopts CART to construct the decision trees, while RF uses a different tree construction method from CART.

$$
m=\sqrt{M}+1
$$

\subsection{Validation and Accuracy Assessment}

Result validation was applied to the four mangroves species using the reference samples described in Section 2.2. Since a supervised classification approach was applied, the reference samples were separated into two parts; model calibration and results validation, with $80 \%$ for training and $20 \%$ for testing. The detailed distribution of all samples among different classes is shown in Table 2. Compared to mangrove species identification, water and mudflat designations were much easier to classify. Therefore, the accuracy would be higher than that using six classes. To represent the accuracy of the classification, the most commonly-used technique is a Confusion Matrix (CM), which is utilized to look into the class confusion between various mangrove species. Two CM-based accuracy indices, the overall accuracy and the kappa coefficient, were calculated. Moreover, since the two decision tree-based methods, RF and RoF, have technical features, a 10-fold cross-validation was performed, and the Student's $t$-test was used to evaluate the significance of classification accuracy from RF and RoF, to assess the contribution of using RoF in this study.

Table 2. Details of the training and testing samples. MUD, mudflat.

\begin{tabular}{cccc}
\hline Class & Training (Samples) & Testing (Samples) & Total (Samples) \\
\hline KO & 80 & 20 & 100 \\
AM & 114 & 29 & 143 \\
AI & 97 & 25 & 122 \\
AC & 52 & 14 & 66 \\
MUD & 105 & 27 & 132 \\
WATER & 124 & 31 & 155 \\
\hline Total & 572 & 146 & 718 \\
\hline
\end{tabular}

\section{Results}

\subsection{Mangrove Species Classification}

The Worldview 3 and Radarsat-2 data were designed in three different groups: (1) original eight-band Worldview 3 data (WV3), (2) original Worldview 3 data and its related spectral and textural Features (WV3F) and (3) WV3F and the polarimetric features described in Section 2 from the Radarsat-2 data (WV3FRS2), using three different machine learning methods, SVM, RF and RoF. Figure 4 compares the mangrove species classification results from different datasets and methods. 

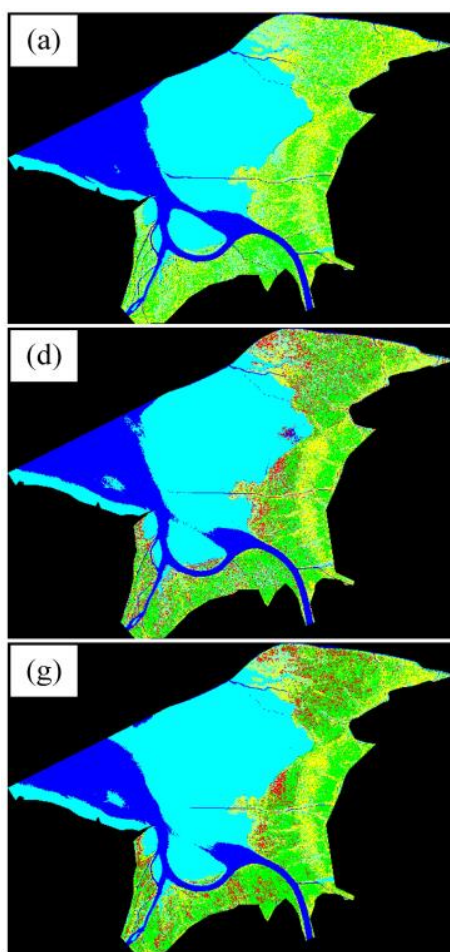

KO

AM
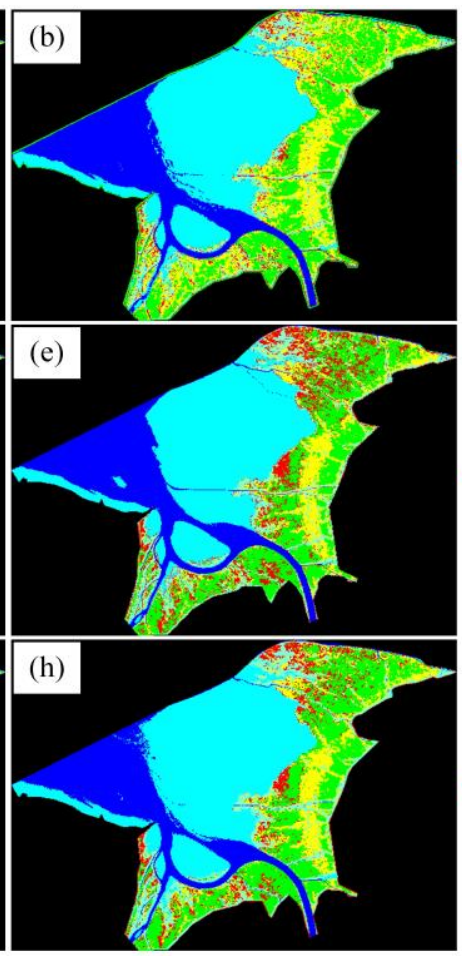

AI

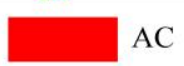

Figure 4. Mangrove species classification using SVM $(\mathbf{a}-\mathbf{c})$, random forest $(\mathbf{d}-\mathbf{f})$ and rotation forest $(\mathbf{g}-\mathbf{i})$ with different datasets; (a,d,g) for original Worldview 3 data (WV3); (b,e,h) for original Worldview 3 data and all related Features (WV3F); (c,f,i) for all the Worldview 3 data, related features and the polarimetric features from Radarsat 2 data (WV3FRS2). WAT denotes Water body and BKG denotes background.

A set of observations is summarized in Figure 4. SVM performed the worst among the three methods, with a notable underestimation of the AC species in all three datasets. When using only the Worldview data (Figure 4a), the AC species cannot be separated from KO and AM. The RoF method obtained the best results for every dataset. Additionally, RF demonstrated moderate performance among the three methods, though some overestimation of AC can be observed from Figure 4e,f. Finally, when using only the WV3 data, the AC species was generally underestimated, and some of the sea water was incorrectly classified as MUD when using RF and RoF. With the additional use of features from WV3, i.e., WV3F, this incorrect MUD was removed when using RoF. However, the advantage from further use of dual polarimetric data cannot be easily recognized from Figure 4. Therefore, a quantitative assessment of the classification was provided in the Section 4.2.

\subsection{Accuracy Assessment of the Classification}

The overall accuracy and kappa coefficient based on the CM were calculated and are compared in Figure 5. Consistent with the results highlighted in Figure 4, the lowest accuracy came from SVM, while the highest accuracy was from RoF. This is also consistent with the datasets of WV3F and WV3FRS2. For the dataset WV3, RF performed the best. Furthermore, both the overall accuracy and kappa coefficient demonstrated the advantages of the use of features from WV3 and dual polarimetric SAR data, with accuracies of WV3 $<$ WV3F $<$ WV3FRS2. This observation indicated that dual polarimetric SAR data were able to compensate optical data to improve the classification of mangrove species, using different machine learning methods. 

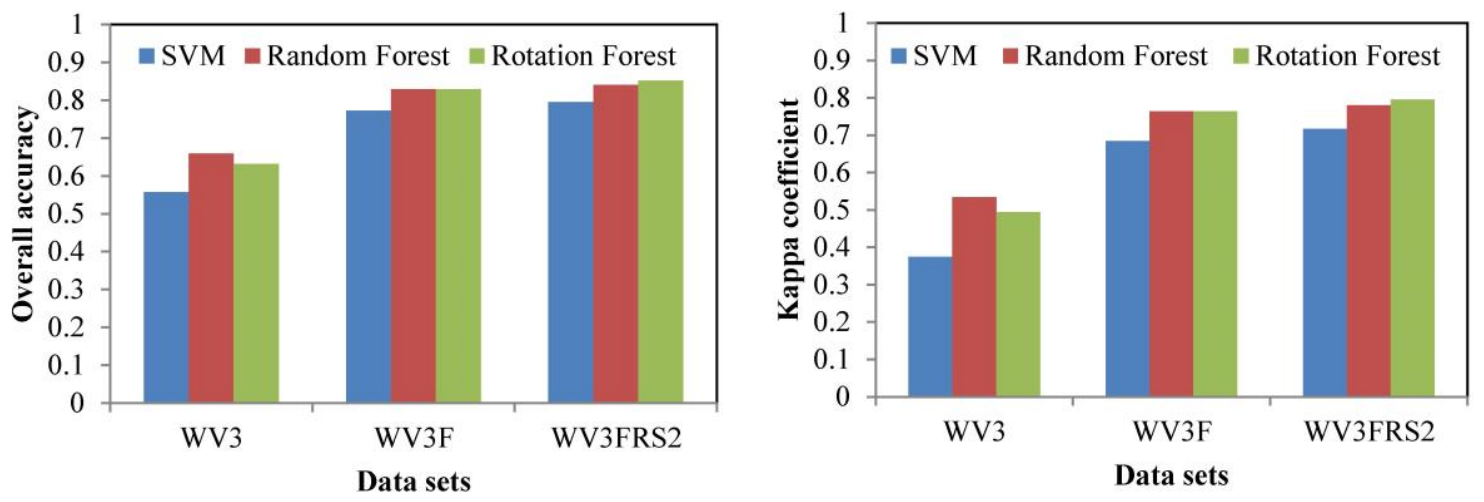

Figure 5. Overall accuracy and kappa coefficient.

For more details about the accuracy assessment, the confusion matrix for all classifications is provided in Table 3, corresponding to the results in Figures 4 and 5. It is consistent that misclassifications of the mangrove species AI and AC were obvious using only the WV3 data for all methods. This misclassification was improved substantially by adding the features from the WV3 data and was further improved after adding the Radarsat- 2 images. The highest accuracy was obtained from RoF using the WV3FRS2 dataset, with an overall accuracy of $85.23 \%$ and a kappa value of 0.7955 .

Table 3. Confusion matrix for mangrove species classifications (in pixels).

\begin{tabular}{|c|c|c|c|c|c|c|c|c|c|c|c|c|c|}
\hline & \multicolumn{2}{|c|}{ Reference } & \multicolumn{2}{|c|}{ WV3 } & \multirow[b]{2}{*}{$A C$} & \multicolumn{4}{|c|}{ WV3F } & \multicolumn{4}{|c|}{ WV3FRS2 } \\
\hline Classi & ied & KO & AM & AI & & KO & AM & AI & AC & KO & $\mathbf{A M}$ & AI & $\mathrm{AC}$ \\
\hline \multirow{5}{*}{ SVM } & KO & 17 & 3 & 0 & 0 & 18 & 0 & 0 & 0 & 17 & 0 & 0 & 0 \\
\hline & AM & 3 & 19 & 12 & 5 & 2 & 26 & 3 & 6 & 3 & 26 & 2 & 6 \\
\hline & AI & 0 & 7 & 13 & 9 & 0 & 3 & 19 & 3 & 0 & 3 & 20 & 1 \\
\hline & AC & 0 & 0 & 0 & 0 & 0 & 0 & 3 & 5 & 0 & 0 & 3 & 7 \\
\hline & & \multicolumn{4}{|c|}{ OA: 55.68\%; kappa: 0.3746} & \multicolumn{4}{|c|}{ OA: 77.27\%; kappa: 0.6842} & \multicolumn{4}{|c|}{ OA: 79.55\%; kappa: 0.7167} \\
\hline \multirow{5}{*}{ RF } & KO & 17 & 3 & 0 & 0 & 18 & 0 & 0 & 0 & 19 & 0 & 0 & 0 \\
\hline & AM & 3 & 20 & 9 & 1 & 2 & 27 & 4 & 3 & 1 & 27 & 4 & 3 \\
\hline & AI & 0 & 3 & 13 & 5 & 0 & 2 & 20 & 3 & 0 & 2 & 20 & 3 \\
\hline & $\mathrm{AC}$ & 0 & 3 & 3 & 8 & 0 & 0 & 1 & 8 & 0 & 0 & 1 & 8 \\
\hline & & \multicolumn{4}{|c|}{ OA: 65.91\%; kappa: 0.5341} & \multicolumn{4}{|c|}{ OA: $82.95 \%$; kappa: 0.7638} & \multicolumn{4}{|c|}{ OA: $84.09 \%$; kappa: 0.7799} \\
\hline \multirow{5}{*}{ RoF } & KO & 18 & 1 & 0 & 1 & 18 & 0 & 0 & 0 & 19 & 0 & 0 & 0 \\
\hline & AM & 2 & 20 & 8 & 3 & 2 & 27 & 3 & 3 & 1 & 28 & 4 & 3 \\
\hline & AI & 0 & 4 & 13 & 6 & 0 & 2 & 21 & 4 & 0 & 1 & 20 & 3 \\
\hline & $\mathrm{AC}$ & 0 & 4 & 3 & 4 & 0 & 0 & 1 & 7 & 0 & 0 & 1 & 8 \\
\hline & & \multicolumn{4}{|c|}{ OA: $63.22 \%$; kappa: 0.4944} & \multicolumn{4}{|c|}{ OA: $82.95 \%$; kappa: 0.7635} & \multicolumn{4}{|c|}{ OA: $85.23 \%$; kappa: 0.7955} \\
\hline
\end{tabular}

In order to further investigate the complementary information from dual polarimetric SAR data regarding different mangrove species, the producer's and user's accuracy of the classification [54,55] using different datasets and different methods are shown in Figure 6. The producer's and user's accuracy indicated that $\mathrm{KO}$ and $\mathrm{AM}$ species were easier to identify compared with other species. All three different datasets can obtain adequate accuracy for $\mathrm{KO}$ and $\mathrm{AM}$ species. $\mathrm{KO}$ and $\mathrm{AM}$ are often taller than AI and AC in the MPMNR mangrove forest, which can be reflected in the reflectance and texture in the WV3 data. However, AI and AC were not identified as easily, especially when using only the WV3 data, where the SVM method was not able to classify AC species. This can also be observed in Figure 4. With the addition of texture and spectral features from the WV3 data, the producer's accuracy and user's accuracy for AI and AC were noticeably increased. Furthermore, by combining the dual polarimetric data, the producer's accuracy of AC was increased. Generally, an order of species 
can be concluded from Figure 6, that is $\mathrm{KO}<\mathrm{AM}<\mathrm{AI}<\mathrm{AC}$, with increasing difficulty of identification from satellite data in this study.
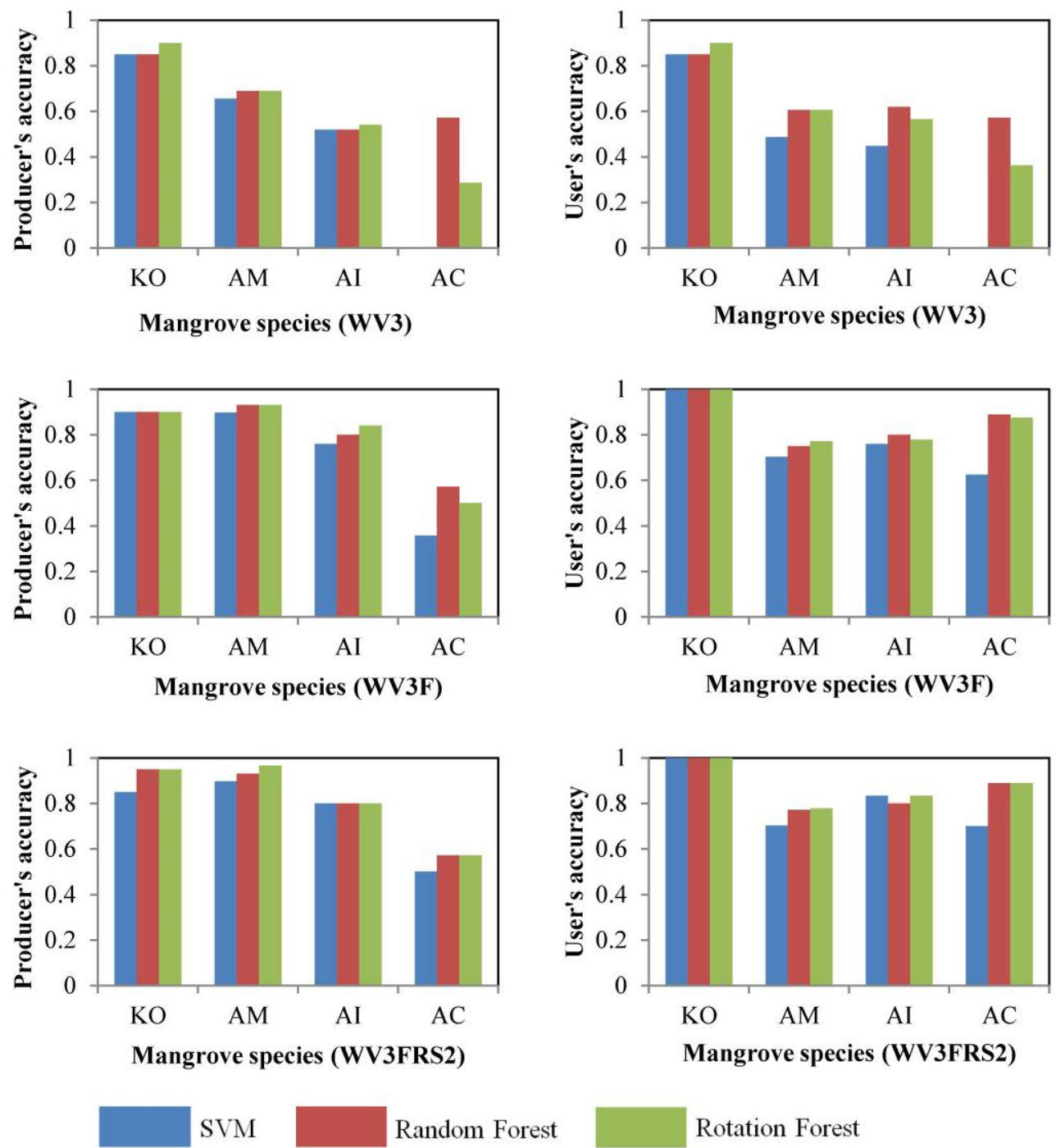

Figure 6. Producer's and user's accuracies of the classification.

\section{Discussion}

\subsection{Contributions from the Dual Polarimetric SAR Data}

Mangrove forests comprise one of the most productive and important ecosystems because they provide important ecological services for shoreline stabilization, habitat provision for invertebrates, fish and other coastal wildlife and carbon sequestration for the ocean. Monitoring the spatial distribution of mangrove forests from remote sensing is imperative to better understand their ecological services, while accurate assessment of the mangroves' distribution remains challenging, especially at the species level. This study assessed the complementary role of SAR data towards optical data for the improvement of mangrove classification. The overall accuracy was improved from $63.22 \%$ (WV3) to $82.95 \%$ (WV3F) and $85.23 \%$ (WV3FRS2), while the kappa coefficient improved from 0.4944 (WV3) to 0.7635 (WV3F) and 0.7955 (WV3FRS2). Although the improvement may be small (about 3\%), it may be important for more efficient large-scale monitoring of mangrove forest. In terms of overall accuracy, for an area of 350 ha of mangroves (the case in this study), a 3\% improvement can be 7-10.5 ha from incorrect mapping to correct mapping. If the mangrove forest reaches $10,000 \mathrm{ha}$, this corrected area can be up to 300 ha. 
This improvement can be further explained from the producer's and user's accuracies over different species, showing that dual polarimetric SAR data mainly contributed to the identification of AI and AC species. Generally, different mangrove species have high spectral confusions in their optical reflectance, leading to the difficulty of accurate classification using optical data alone. However, SAR is sensitive to the geometric properties of different species, including tree height, shape and size of leaves and shape and size of the canopy. For instance, $\mathrm{KO}$ is often among the tallest trees in the mangrove community, while AI often locates at the bottom layer. AM and AC appears similar in their size and shape of the leaves. All these geometric properties can be easier reflected in SAR data and thus compensate the classification of different species. Regarding the backscattering mechanism, the dominant scattering of microwave (e.g., C-band in this study) depends greatly on the mangrove height and biomass, which have been reported to vary significantly among different mangrove species [20,22,41,42]. For instance, the biomass of $\mathrm{KO}$ is much higher than AM, while the biomass of AC is higher than $\mathrm{KO}$ in the study area [41,42], which can be reflected in the backscattering coefficient of the dual-polarization C-band SAR data.

\subsection{Factors Affecting Accuracy Assessment}

Due to the mangrove forest conservation policy of the local government, reference data collection is often limited, and thus, large amounts of reference data are difficult to collect. Consequently, small sample sizes of reference samples are typical $[16,35,56,57]$. In this study, only 718 samples were collected over the MPMNR, among which $80 \%$ were used for training the classifiers and $20 \%$ for validation and accuracy assessment (see Table 2). The small size of mangrove species samples of field data in MPMNR using remote sensing was also reported in previous literature [16,35]. However, this small sample size may decrease the reliability of the accuracy assessment from a statistical point of view. In this study, the classification results derived from the combined SAR and optical data (WV3FRS2) using RF and RoF are noticeably better than the results from other data combinations with all three methods (Table 3). However, the accuracy from WV3FRS2 and RF (OA: 84.09\%; kappa: 0.7799) and the accuracy from WV3FRS2 and RoF (OA: 85.23\%; kappa: 0.7955) are close, indicating a possible small improvement from using RoF compared with RF. In order to assess the significance of this improvement, we further conducted a 10-fold cross-validation classification of WV3FRS2 data using RoF and RF (Table 4). The OA of RF varied from $76.74-88.37 \%$ with a mean of $82.36 \%$, while the OA using RoF varied from $76.74-90.70 \%$ with a mean of $85.61 \%$. The kappa coefficient from RF varied from $0.6747-0.8404$ with a mean of 0.7567 , while the kappa value from RoF from $0.6866-0.8720$ with a mean of 0.8021 . The standard deviation of OA from RoF is less than that from RF, indicating that RoF is more stable. Furthermore, a Student's t-test was applied to the OA and kappa coefficient. The $t$-value is 0.0096 for the OA values and 0.0087 for the kappa values between RF and RoF, indicating that the accuracies from these two methods are significantly different, and thus, the improvement of RoF over RF is significant.

Table 4. Statistics of accuracy assessment from a 10-fold cross-validation using RF and RoF.

\begin{tabular}{cccccc}
\hline \multicolumn{2}{c}{ WV3FRS2 } & Minimum & Maximum & Mean & Standard Deviation \\
\hline \multirow{2}{*}{ RF } & OA & $76.74 \%$ & $88.37 \%$ & $82.36 \%$ & 4.69 \\
& Kappa & 0.6747 & 0.8404 & 0.7567 & 0.06 \\
\hline \multirow{2}{*}{ RoF } & OA & $76.74 \%$ & $90.70 \%$ & $85.61 \%$ & 4.38 \\
& Kappa & 0.6866 & 0.8720 & 0.8021 & 0.06 \\
\hline
\end{tabular}

\subsection{Comments about Datasets and Methods}

In this study, the potential benefits of combining SAR and optical data for improving mangrove species classification in this manuscript were investigated. There are two main practical reasons. First, regarding the SAR datasets, only dual polarimetric SAR data were used. Fully-polarimetric SAR data could have provided much more backscattering features of different species, but the majority of currently-available SAR data, such as the free-access Sentinel-1 data, are dual polarimetric. Investigating 
the dual polarimetric SAR data can also be useful for practical use, especially for those cases with only free-access SAR data. With the increasing availability of SAR data free to the public (e.g., Sentinel 1 and ALOS), a large amount of SAR data at different resolutions is ready to be used covering the whole Earth's surface. Thus, it is practical to support operational mangrove forest monitoring efforts. Moreover, the processing and computation of such big SAR data are also being constantly improved with a rapid development of various machine learning techniques (e.g., deep learning). Therefore, the cost of adding SAR data as an additional dataset is not very high for mangrove species classification and is worth the effort even for the small improvements in accuracy found here. Considering the benefits derived from increasing accuracy, it should be useful to add polarimetric SAR data to compensate optical data for improving species classification of mangroves.

Second, regarding the methodology, there are many promising methods that still have not been applied to mangrove species classification from a combined dataset of multi-source remote sensing data. However, it is a gradual procedure to test and validate the new and advanced methods to improve the species classification step by step. In this paper, the Rotation Forest (RoF) method is employed, as we hypothesized that it can be more useful than the frequently-used Random Forest (RF). Specifically, three typical methods were compared: SVM, RF and RoF. Although SVM has been one of the most popular classifiers with wide applications, it did not demonstrate good performance compared with RF and RoF. This may be caused by the high confusion among different mangrove species, leading to difficulty in learning the support vectors. However, RF and RoF were based on the ensemble of decision trees, which can be made more robust for non-linear and highly confused classes. Furthermore, different classifiers performed differently over the species. For instance, as observed from the experiments, RoF is more useful for identifying $\mathrm{KO}$ and $\mathrm{AM}$ species, while RF is more helpful for classifying AC species. Therefore, it would be useful to further investigate the advantages and disadvantages of each classifier over different mangrove species.

\section{Conclusions}

Discrimination of mangrove species using satellite remote sensing is challenging due to factors such as spatial resolution, species number and spectral confusion between species. This study investigated the potential of the Worldview-3 with an eight-band product and Radarsat-2 with a dual-polarimetric SAR product for mangrove species classification. Three different combinations of datasets were designed, including WV3, WV3F and WV3FRS2. Then, RoF was applied to classify the four mangrove species. Experiments indicated the effectiveness of different datasets with an increasing accuracy as WV3 $<$ WV3F $<$ WV3FRS2, showing the benefits of dual polarimetric SAR data. Additionally, the difficulty of classifying different mangrove species was also identified as $\mathrm{KO}<\mathrm{AM}<\mathrm{AI}<\mathrm{AC}$, in order of increasing difficulty. Dual polarimetric SAR data were recognized to improve the classification of $\mathrm{AI}$ and AC species. Moreover, RoF turned out to be more suitable than SVM and RF. Although this improvement is not remarkable, the improvement is consistent for all three methods. Furthermore, a 10-fold cross-validation with a Student's $t$-test was performed and indicated that the improvement of using RoF is statistically significant compared with RF. The improvement can be particularly important for large-scale mapping of mangrove forest at the species level. These findings also provide useful references for future studies using multi-source satellite data for mangrove monitoring and conservation.

Acknowledgments: This study was jointly supported by the National Natural Science Foundation of China (41401370 and 41671378), the Collaborative Innovation Center for Major Security Issues of Jiangxi Province and Monitoring Implementation (No. JXS-EW-00), the Research Grants Council (RGC) General Research Fund (CUHK 14601515, CUHK 14635916 and CUHK 14605917) and the Key Laboratory of Spatial Data Mining \& Information Sharing of Ministry of Education, Fuzhou University (No. 2016LSDMIS02).

Author Contributions: H.Z., T.W. and H.L. conceived of and designed the experiments. H.Z. and M.L. performed the experiments. M.J., H.L., L.M.C. and A.T.D. analyzed the data and results. H.Z. wrote the paper. A.T.D. revised and edited the paper. 
Conflicts of Interest: The authors declare no conflict of interest. The founding sponsors had no role in the design of the study; in the collection, analyses or interpretation of data; in the writing of the manuscript; nor in the decision to publish the results.

\section{References}

1. Giri, C.; Ochieng, E.; Tieszen, L.L.; Zhu, Z.; Singh, A.; Loveland, T.; Masek, J.; Duke, N. Status and distribution of mangrove forests of the world using earth observation satellite data. Glob. Ecol. Biogeogr. 2011, 20, 154-159. [CrossRef]

2. Duke, N.C.; Meynecke, J.O.; Dittmann, S.; Ellison, A.M.; Anger, K.; Berger, U.; Cannicci, S.; Diele, K.; Ewel, K.C.; Field, C.D.; et al. A world without mangroves? Science 2007, 317, 41-42. [CrossRef] [PubMed]

3. Heumann, B.W. Satellite remote sensing of mangrove forests: Recent advances and future opportunities. Prog. Phys. Geogr. 2011, 35, 87-108. [CrossRef]

4. Rogers, K.; Lymburner, L.; Salum, R.; Brooke, B.P.; Woodroffe, C.D. Mapping of mangrove extent and zonation using high and low tide composites of Landsat data. Hydrobiologia 2017, 803, 49-68. [CrossRef]

5. Bullock, E.L.; Fagherazzi, S.; Nardin, W.; Vo-Luong, P.; Nguyen, P.; Woodcock, C.E. Temporal patterns in species zonation in a mangrove forest in the mekong delta, vietnam, using a time series of Landsat imagery. Cont. Shelf Res. 2017, 147, 144-154. [CrossRef]

6. Wang, L.; Sousa, W.P.; Gong, P. Integration of object-based and pixel-based classification for mapping mangroves with ikonos imagery. Int. J. Remote Sens. 2004, 25, 5655-5668. [CrossRef]

7. Wang, L.; Sousa, W.P.; Gong, P.; Biging, G.S. Comparison of Ikonos and Quickbird images for mapping mangrove species on the caribbean coast of panama. Remote Sens. Environ. 2004, 91, 432-440. [CrossRef]

8. Heenkenda, M.K.; Joyce, K.E.; Maier, S.W.; Bartolo, R. Mangrove species identification: Comparing Worldview-2 with aerial photographs. Remote Sens. 2014, 6, 6064-6088. [CrossRef]

9. Heumann, B.W. An object-based classification of mangroves using a hybrid decision tree-support vector machine approach. Remote Sens. 2011, 3, 2440-2460. [CrossRef]

10. Wang, T.; Zhang, H.S.; Lin, H.; Fang, C.Y. Textural-spectral feature-based species classification of mangroves in Mai Po Nature Reserve from Worldview-3 imagery. Remote Sens. 2016, 8, 24. [CrossRef]

11. Wan, L.; Zhang, H.; Wang, T.; Li, G.; Lin, H. Mangrove species discrimination from very high resolution imagery using gaussian markov random field model. Wetlands 2017. accepted.

12. Wang, L.; Sousa, W.P. Distinguishing mangrove species with laboratory measurements of hyperspectral leaf reflectance. Int. J. Remote Sens. 2009, 30, 1267-1281. [CrossRef]

13. Kamal, M.; Phinn, S. Hyperspectral data for mangrove species mapping: A comparison of pixel-based and object-based approach. Remote Sens. 2011, 3, 2222-2242. [CrossRef]

14. Adam, E.; Mutanga, O.; Rugege, D. Multispectral and hyperspectral remote sensing for identification and mapping of wetland vegetation: A review. Wetl. Ecol. Manag. 2010, 18, 281-296. [CrossRef]

15. Jia, M.M.; Wang, Z.M.; Zhang, Y.Z.; Ren, C.Y.; Song, K.S. Landsat-based estimation of mangrove forest loss and restoration in guangxi province, china, influenced by human and natural factors. IEEE J. STARS 2015, 8 , 311-323. [CrossRef]

16. Jia, M.M.; Zhang, Y.Z.; Wang, Z.M.; Song, K.S.; Ren, C.Y. Mapping the distribution of mangrove species in the core zone of mai po marshes nature reserve, hong kong, using hyperspectral data and high-resolution data. Int. J. Appl. Earth Obs. 2014, 33, 226-231. [CrossRef]

17. Rahman, A.F.; Dragoni, D.; Didan, K.; Barreto-Munoz, A.; Hutabarat, J.A. Detecting large scale conversion of mangroves to aquaculture with change point and mixed-pixel analyses of high-fidelity modis data. Remote Sens. Environ. 2013, 130, 96-107. [CrossRef]

18. Mougin, E.; Proisy, C.; Marty, G.; Fromard, F.; Puig, H.; Betoulle, J.L.; Rudant, J.P. Multifrequency and multipolarization radar backscattering from mangrove forests. IEEE Trans. Geosci. Remote Sens. 1999, 37, 94-102. [CrossRef]

19. Proisy, C.; Mougin, E.; Fromard, F.; Karam, M.A. Interpretation of polarimetric radar signatures of mangrove forests. Remote Sens. Environ. 2000, 71, 56-66. [CrossRef]

20. Kumar, T.; Patnaik, C. Discrimination of mangrove forests and characterization of adjoining land cover classes using temporal C-band synthetic aperture radar data: A case study of sundarbans. Int. J. Appl. Earth Obs. 2013, 23, 119-131. [CrossRef] 
21. Lucas, R.M.; Mitchell, A.L.; Rosenqvist, A.; Proisy, C.; Melius, A.; Ticehurst, C. The potential of 1-band sar for quantifying mangrove characteristics and change: Case studies from the tropics. Aquat. Conserv. 2007, 17, 245-264. [CrossRef]

22. Simard, M.; Zhang, K.Q.; Rivera-Monroy, V.H.; Ross, M.S.; Ruiz, P.L.; Castaneda-Moya, E.; Twilley, R.R.; Rodriguez, E. Mapping height and biomass of mangrove forests in everglades national park with srtm elevation data. Photogramm. Eng. Remote Sens. 2006, 72, 299-311. [CrossRef]

23. Kalogirou, V.; Ferrazzoli, P.; Della Vecchia, A.; Foumelis, M. On the SAR backscatter of burned forests: A model-based study in C-band, over burned pine canopies. IEEE Trans. Geosci. Remote Sens. 2014, 52, 6205-6215. [CrossRef]

24. Picard, G.; Le Toan, T.; Mattia, F. Understanding C-band radar backscatter from wheat canopy using a multiple-scattering coherent model. IEEE Trans. Geosci. Remote Sens. 2003, 41, 1583-1591. [CrossRef]

25. De Roo, R.D.; Du, Y.; Ulaby, F.T.; Dobson, M.C. A semi-empirical backscattering model at L-band and C-band for a soybean canopy with soil moisture inversion. IEEE Trans. Geosci. Remote Sens. 2001, 39, 864-872. [CrossRef]

26. Fransson, J.E.S.; Israelsson, H. Estimation of stem volume in boreal forests using ERS-1 C- and jers-1 L-band SAR data. Int. J. Remote Sens. 1999, 20, 123-137. [CrossRef]

27. Hamdan, O.; Aziz, H.K.; Hasmadi, I.M. L-band ALOS PALSAR for biomass estimation of matang mangroves, malaysia. Remote Sens. Environ. 2014, 155, 69-78. [CrossRef]

28. Kovacs, J.M.; Vandenberg, C.V.; Wang, J.; Flores-Verdugo, F. The use of multipolarized spaceborne SAR backscatter for monitoring the health of a degraded mangrove forest. J. Coast. Res. 2008, 24, 248-254. [CrossRef]

29. Zhang, H.S.; Xu, R. Exploring the optimal integration levels between SAR and optical data for better urban land cover mapping in the pearl river delta. Int. J. Appl. Earth Obs. 2018, 64, 87-95. [CrossRef]

30. Zhang, H.S.; Lin, H.; Li, Y.; Zhang, Y.Z.; Fang, C.Y. Mapping urban impervious surface with dual-polarimetric SAR data: An improved method. Landsc. Urban Plan. 2016, 151, 55-63. [CrossRef]

31. Zhang, H.S.; Lin, H.; Zhang, Y.Z.; Weng, Q.H. Remote Sensing of Impervious Surfaces in Tropical and Subtropical Areas; CRC Press: Boca Raton, FL, USA, 2015.

32. Souza, P.W.M.; Paradella, W.R. Use of radarsat-1 fine mode and Landsat-5 tm selective principal component analysis for geomorphological mapping in a macrotidal mangrove coast in the amazon region. Can. J. Remote Sens. 2005, 31, 214-224. [CrossRef]

33. Kovacs, J.M.; Zhang, C.; Flores-Verdugo, F.J. Mapping the condition of mangroves of the mexican pacific using C-band envisat asar and landsat optical data. Cienc. Mar. 2008, 34, 407-418. [CrossRef]

34. Wong, F.K.K.; Fung, T. Combining hyperspectral and radar imagery for mangrove leaf area index modeling. Photogramm. Eng. Remote Sens. 2013, 79, 479-490. [CrossRef]

35. Wong, F.K.K.; Fung, T. Combining eo-1 hyperion and ENVISAT ASAR data for mangrove species classification in mai po ramsar site, hong kong. Int. J. Remote Sens. 2014, 35, 7828-7856. [CrossRef]

36. AFCD. Mai Po Inner Deep Bay Ramsar Site Management Plan Executive Summary; Agriculture, Fisheries and Conservation Department (AFCD): Hong Kong, China, 2011.

37. Zhang, Y.Z.; Zhang, H.S.; Lin, H. Improving the impervious surface estimation with combined use of optical and SAR remote sensing images. Remote Sens. Environ. 2014, 141, 155-167. [CrossRef]

38. Wells, S.; Ravilious, C.; Corcoran, E. In the Front-Line: Shoreline Protection and Other Ecosystem Services from Mangroves and Coral Reefs; The UN Environment World Conservation Monitoring Centre (UNEP-WCMC): Cambridge, UK, 2006.

39. Tam, N.F.Y.; Wong, Y.S. Hong Kong Mangroves; City University of Hong Kong Press: Hong Kong, China, 2000.

40. Tam, N.F.Y.; Wong, Y.S.; Lu, C.Y.; Berry, R. Mapping and characterization of mangrove plant communities in Hong Kong. Hydrobiologia 1997, 352, 25-37. [CrossRef]

41. Peng, C.; Qian, J.; Guo, X.; Zhao, H.; Hu, N.; Yang, Q.; Chen, L. Vegetative carbon stocks and net primary productivity of the mangrove forests in shenzhen, china. Chin. J. Appl. Ecol. 2016, 27, 2059-2065.

42. Tam, N.F.Y.; Wong, Y.S.; Lan, C.Y.; Chen, G.Z. Community structure and standing crop biomass of a mangrove forest in futian nature-reserve, shenzhen, china. Hydrobiologia 1995, 295, 193-201. [CrossRef]

43. Goward, S.N.; Markham, B.; Dye, D.G.; Dulaney, W.; Yang, J.L. Normalized difference vegetation index measurements from the advanced very high-resolution radiometer. Remote Sens. Environ. 1991, 35, 257-277. [CrossRef]

44. McFeeters, S.K. The use of the normalized difference water index (ndwi) in the delineation of open water features. Int. J. Remote Sens. 1996, 17, 1425-1432. [CrossRef] 
45. Haralick, R.M.; Shanmuga, K.; Dinstein, I. Textural features for image classification. IEEE Trans. Syst. Man Cybern. 1973, Smc3, 610-621. [CrossRef]

46. Cloude, S.R. The Dual Polarisation Entropy/Alpha Decomposition: A Palsar Case Study. 2007. Available online: http:/ / earth.esa.int/workshops/polinsar2007/papers/75_cloude.pdf (accessed on 26 January 2007).

47. Cloude, S.R.; Pottier, E. An entropy based classification scheme for land applications of polarimetric sar. IEEE Trans. Geosci Remote Sens. 1997, 35, 68-78. [CrossRef]

48. Rodriguez, J.J.; Kuncheva, L.I. Rotation forest: A new classifier ensemble method. IEEE Trans. Pattern Anal. Mach. Intell. 2006, 28, 1619-1630. [CrossRef] [PubMed]

49. Du, P.J.; Samat, A.; Waske, B.; Liu, S.C.; Li, Z.H. Random forest and rotation forest for fully polarized sar image classification using polarimetric and spatial features. ISPRS J. Photogramm. 2015, 105, 38-53. [CrossRef]

50. Vapnik, V. The Nature of Statistical Learning Theory; Springer: New York, NY, USA, 1995.

51. Breiman, L. Random forests. Mach. Learn. 2001, 45, 5-32. [CrossRef]

52. Zhang, H.S.; Zhang, Y.Z.; Lin, H. A comparison study of impervious surfaces estimation using optical and sar remote sensing images. Int. J. Appl. Earth Obs. 2012, 18, 148-156. [CrossRef]

53. Weston, J.; Watkins, C. Support Vector Machines for Multi-Class Pattern Recognition. In Proceedings of the 7th European Symposium on Artificial Neural Networks, Bruges, Belgium, 21-23 April 1999; Verleysen, M., Ed.; D-Facto: Bruges, Belgium, 1999.

54. Jensen, J.R. Introductory Digital Image Processing: A Remote Sensing Perspective, 3rd ed.; Pearson Education Ltd.: London, UK, 2007.

55. Zhang, H.S.; Lin, H.; Li, Y.; Zhang, Y.Z. Feature extraction for high-resolution imagery based on human visual perception. Int. J. Remote Sens. 2013, 34, 1146-1163. [CrossRef]

56. Luo, Y.M.; Huang, D.T.; Liu, P.Z.; Feng, H.M. An novel random forests and its application to the classification of mangroves remote sensing image. Multimed. Tools Appl. 2016, 75, 9707-9722. [CrossRef]

57. Jia, M.M.; Wang, Z.M.; Li, L.; Song, K.S.; Ren, C.Y.; Liu, B.; Mao, D.H. Mapping china's mangroves based on an object-oriented classification of Landsat imagery. Wetlands 2014, 34, 277-283. [CrossRef]

(C) 2018 by the authors. Licensee MDPI, Basel, Switzerland. This article is an open access article distributed under the terms and conditions of the Creative Commons Attribution (CC BY) license (http:/ / creativecommons.org/licenses/by/4.0/). 